\title{
Ethanol-Induced Gastric Injury: Microscopic Analysis of the Protective Effect of Frutalin
}

\author{
Ana Paula Vasconcellos Abdon • Renata Prado Vasconcelos • Carolina Araújo Castro • \\ Marjorie Moreira Guedes • Adriana da Rocha Tomé • André Luiz Herzog Cardoso • \\ Thiago de Melo Santiago • Luciana Magalhães Rebêlo $\cdot$ Renato de Azevedo Moreira • \\ Ana Cristina de Oliveira Monteiro-Moreira • Adriana Rolim Campos
}

Accepted: 31 January 2014/Published online: 16 February 2014

(C) Springer Science+Business Media New York 2014

\begin{abstract}
Obtained from breadfruit seeds (Artocarpus incisa), frutalin (FTL) has a range of important pharmacological properties. FTL activates and modulates lymphocytes and neutrophils and possesses gastroprotective effects. The purpose of this study was to evaluate the ability of FTL to protect the gastric mucosa of mice submitted to ethanolinduced gastric injury. The gastroprotective effect of frutalina was evaluated using a murine model of ethanol-induced gastric injury. Damage of the gastric mucosa was assessed morphologically by light, scanning electron and atomic force microscopy. Lymphocyte infiltration, necrosis, disruption of the mucosal structures and epithelial desquamation were observed in the control group. In the group pretreated with frutalina at $0.5 \mathrm{mg} / \mathrm{kg}$, gastroprotection, reduced tissue damage and preserved submucosal and mucosal structures
\end{abstract}

A. P. V. Abdon - R. P. Vasconcelos - C. A. Castro ·

R. A. Moreira - A. C. O. Monteiro-Moreira .

A. R. Campos $(\square)$

RENORBIO, University of Fortaleza (UNIFOR), Av

Washington Soares 1321, Fortaleza, Ceará CEP 60811-905,

Brazil

e-mail: adrirolim@unifor.br

\section{M. Guedes}

Department of Physiology and Pharmacology, Federal

University of Ceará (UFC), Fortaleza, Ceará 60430-270, Brazil

M. M. Guedes - T. M. Santiago - L. M. Rebêlo

Department of Physics, Federal University of Ceará (UFC),

Fortaleza, Ceará 60455-900, Brazil

A. R. Tomé

Veterinarian School, State University of Ceará (UECE),

Fortaleza, Ceará 60740-000, Brazil

A. L. H. Cardoso

Science and Technology Center, State University of Ceará

(UECE), Fortaleza, Ceará 60740-000, Brazil were observed. In conclusion, FTL displayed gastroprotective activity against ethanol-induced gastric injury, preventing the formation of gastric ulcer and reducing epithelial desquamation, glandular damage, mucosal necrosis and infiltration. The observed effects appear to be due to mechanisms previously described for frutalin.

Keywords Artocarpus incisa - Frutalin . Gastroprotective · Ethanol-induced gastric injury · Microscopic analysis

\section{Introduction}

The gastric mucosa consists of different cell populations undergoing constant renewal. Mucosal integrity is maintained by a balance between aggressive factors (such as pepsin and acid secretion) and a number of defense mechanisms (such as bicarbonate and mucus secretion and prostaglandin production) (Abdel-Salam et al. 2001).

Gastric ulcer may be caused by an array of external aggressive factors, including infection with Helicobacter pylori, indiscriminate use of NSAIDs, smoking and alcohol consumption (Abdel-Salam et al. 2001).

Currently, gastric ulcer is treated with several classes of drugs, including antiacids, anticholinergic agents, proton pump inhibitors and $\mathrm{H}_{2}$-receptor antagonists. However, the large number of adverse effects associated with these drugs indicates a need for safer and more effective anti-gastric ulcer agents (Vera-Arzave et al. 2012). More recently, research on metabolites derived from plants used in traditional medicine has led to the discovery and development of novel therapeutic drugs (Sánchez-Mendoza et al. 2011).

Phytogenic agents have traditionally been used by herbalists and indigenous healers for the prevention and 
treatment of peptic ulcer. Despite advances in the production of effective drugs by conventional chemistry and pharmacology, the plant kingdom remains a treasury of unexplored compounds with potential healing properties. Some of these compounds may be useful in the treatment of gastric ulcer or as dietary adjuncts to existing therapies (Borrelli and Izzo 2000).

The breadfruit (Artocarpus incisa L.) is a common species of flowering tree found in tropical regions around the world. The fruit may be consumed roasted, baked, fried or boiled, but is generally cooked by local populations (Jagtap and Bapat 2010). Frutalin (FTL), an $\alpha$-D-galactosebinding lectin purified from $A$. incisa seeds, shares many structural characteristics with other galactose-binding Artocarpus lectins, such as jacalin (A. integrifolia), a wellknown specific ligand of IgA1 and $\mathrm{C} 1$ inhibitors (BrandoLima et al. 2005). Unlike most other lectins, FTL has a rather broad specificity and interacts with galactose and other sugars, such as mannose (Moreira et al. 1998). Physico-chemical and biological studies found higher levels of hemagglutinating activity for FTL than for jacalin. In addition, FTL is a potent human lymphocyte stimulator (Campana et al. 2002).

In a previous study, FTL was found to be gastroprotective against gastric mucosal injury induced by ethanol and indomethacin. The observed gastroprotection to some extent involves the activation of capsaicin-sensitive gastric afferents, stimulation of endogenous prostaglandins and nitric oxide (NO), and the opening of $\mathrm{K}_{\mathrm{ATP}}^{+}$channels (Abdon et al. 2012).

The purpose of this study was to evaluate the ability of FTL to protect the gastric mucosa of mice submitted to ethanol-induced gastric injury.

\section{Materials and Methods}

Animals

Male Swiss albino mice (20-25 g) were obtained from the experimental animal facility of the University of Fortaleza (UNIFOR). The animals were housed under environmentally controlled conditions $\left(22^{\circ} \mathrm{C}, 12\right.$-h light/dark cycle), with free access to standard pellet diet (Purina, São Paulo, Brazil) and water. The cages were fitted with raised mesh bottoms to prevent coprophagy. Prior to the experiment, the mice were fasted for $12 \mathrm{~h}$. The experimental protocols were in accordance with the ethical guidelines of the Brazilian Council for the Control of Animal Experiments (CONCEA) and were approved by the Animal Research Ethics Committee of the State University of Ceará, under entry \#08476547-0.
Frutalin Purification

Highly purified lectin was obtained from breadfruit seeds as described elsewhere (Moreira et al. 1998). Briefly, the seeds were dried, ground and immersed in phosphate buffer solution [pH 7.4 phosphate-buffered saline (PBS)] at 1:10 $\mathrm{w} / \mathrm{v}$. The solution was stirred for $6 \mathrm{~h}$ at $4{ }^{\circ} \mathrm{C}$, then centrifuged for $20 \min \left(1,500 \times \mathrm{g} / 4{ }^{\circ} \mathrm{C}\right)$. The supernatant was ultrafiltrated through a YM10 membrane to half its original volume. FTL (MW $44 \mathrm{kDa}$ ) was purified from this crude extract on a sepharose-D-galactose column eluted with $0.2 \mathrm{M}$ D-galactose in PBS. After extensive dialysis against water, the eluted material was lyophilized and stored at $-20{ }^{\circ} \mathrm{C}$. Just before use, FTL was dissolved in sterile PBS, $\mathrm{pH}$ 6.8. The protein concentration was determined with Bradford's method and purity was confirmed by the presence of only two bands (15.5 and $12 \mathrm{kDa}$ ) following SDSPAGE.

Pretreatment and Ethanol-Induced Gastric Injury

The mice were randomly assigned to 5 groups of 8 animals each for pretreatment with either saline solution, cimetidine or FTL 30 min prior to induction of gastric injury by oral administration of absolute ethanol $(96 \%, 0.2 \mathrm{~mL} /$ animal) (Robert et al. 1979):

Group A: Pretreatment with saline solution $(0.9 \%$ $\mathrm{NaCl}, 10 \mathrm{~mL} / \mathrm{kg}$, p.o.)

Group B: Pretreatment with cimetidine $(100 \mathrm{mg} / \mathrm{kg}$, p.o.)

Group C: Pretreatment with FTL $(0.25 \mathrm{mg} / \mathrm{kg}$, i.p.)

Group D: Pretreatment with FTL $(0.5 \mathrm{mg} / \mathrm{kg}$, i.p.)

Group E: Pretreatment with FTL $(1 \mathrm{mg} / \mathrm{kg}$, i.p.)

Thirty minutes after induction of gastric injury, the animals were euthanized and the stomachs were excised, opened along the greater curvature and rinsed with saline solution $(0.9 \% \mathrm{NaCl})$.

\section{Light Microscopy}

The glandular stomach was fixed in $10 \%$ neutral-buffered formalin solution, sectioned and embedded in paraffin. Four-micrometer thick sections were deparaffinized, stained with hematoxylin and eosin and examined under a light microscope (Silva et al. 2010). Subsequently, the sections were evaluated by an experienced, blinded pathologist for signs of injury (edema, erosion, ulceration and necrosis). 
Fig. 1 Histological analysis by light microscopy of gastric tissues in a model of ethanolinduced gastric injury.

Magnification $\times 20$. a Saline solution (negative control,

Group A), b cimetidine at $100 \mathrm{mg} / \mathrm{kg}$ (positive control, Group B), c FTL at $0.25 \mathrm{mg} / \mathrm{kg}$ (Group C), d FTL at $0.5 \mathrm{mg} / \mathrm{kg}$ (Group D), and e FTL at $1.0 \mathrm{mg} / \mathrm{kg}$ (Group E)
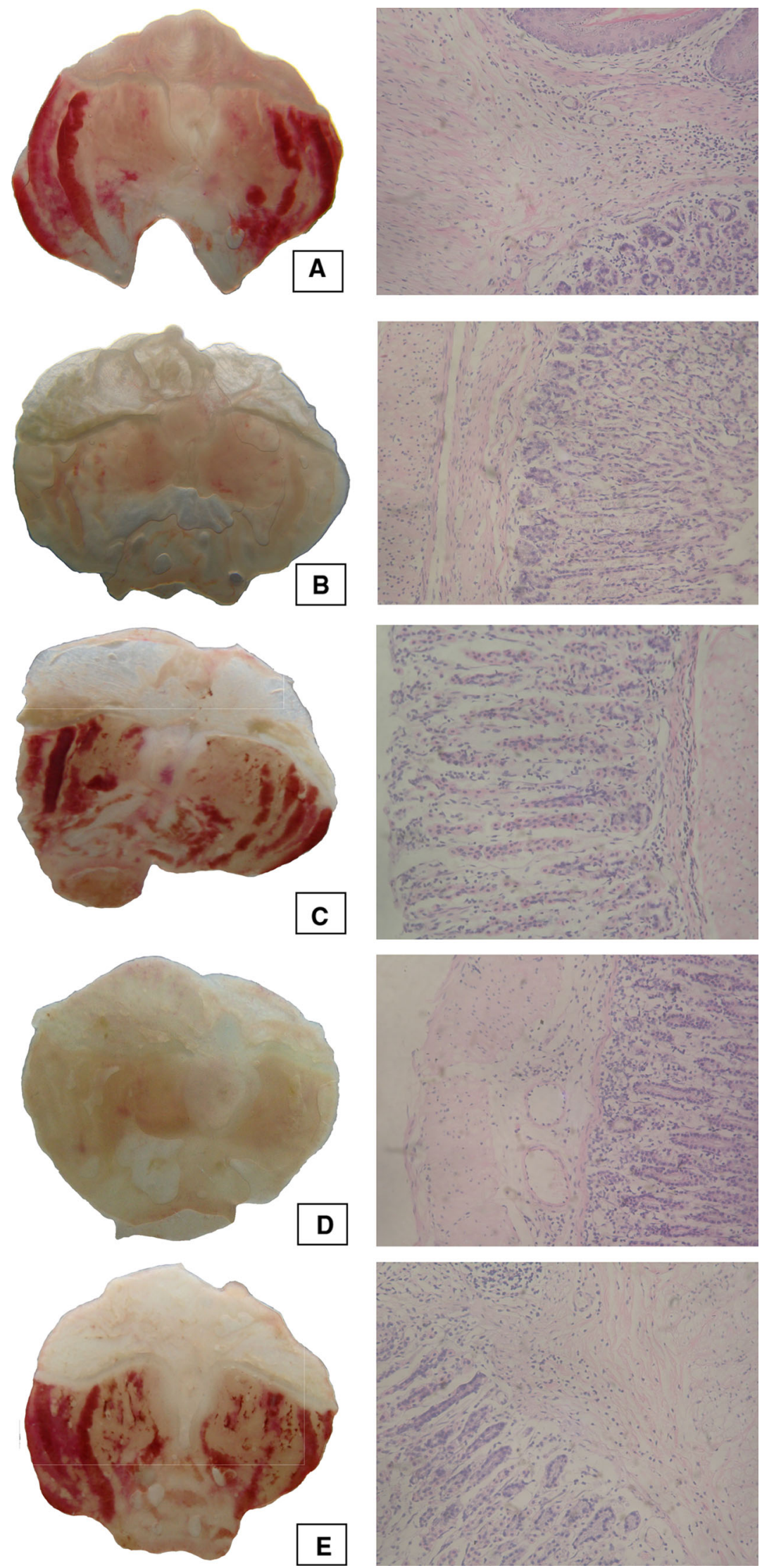
Scanning Electron Microscopy (SEM)

Tissue samples were washed gently with PBS and fixed in $3 \%$ glutaraldehyde overnight at $4{ }^{\circ} \mathrm{C}$, then washed in $0.1 \mathrm{M}$ cacodylate buffer ( $\mathrm{pH} 7.3$ ) and post-fixed with $1 \%$ osmium tetroxide in cacodylate buffer. After another wash in buffer, the samples were immersed in $2 \%$ tannic acid in cacodylate buffer, washed in water and fixed again in $1 \%$ osmium tetroxide in water, followed by dehydration through increasing alcohol gradients (25-100\%). The dehydrated samples were then submitted to critical point drying, mounted on aluminum stubs, coated with a thin layer of gold using a Polaron-ES 100 sputter-coating apparatus and examined in a SEM (Johnson et al. 1983).

\section{Atomic Force Microscopy (AFM)}

Samples for AFM analysis were prepared following the same procedure described above for light microscopy, except for a slight modification in section thickness $(5 \mu \mathrm{m})$. The samples were analyzed in a Nanoscope III AFM (Digital Instruments) operating in tapping mode, using TESP7 silicon nitride tips (Veeco NanProbe). The resolution was set to $512 \times 512$ pixels. The images were processed with the Nanoscope software (v. 5.12.r3) and further analyzed with the software Image-Pro Plus 4.5 (Media Cybernetic) (Deacon et al. 2000).

\section{Results}

\section{Light Microscopy}

Figure 1 shows light micrographs of the mucosa $30 \mathrm{~min}$ after administration of $0.2 \mathrm{~mL}$ absolute ethanol. The animals in Group A (negative control) presented intense lymphocyte infiltration, epithelial desquamation and edema. In addition to these symptoms, the animals in Group $\mathrm{C}$ and $\mathrm{E}$ presented necrosis and disruption of the gastric mucosa.

However, the animals in Group B (positive controls) (Fig. 1b) and Group D (Fig. 1d) had preserved mucosa and reduced levels of lymphocyte infiltration and edema, indicating a significant gastroprotective effect.

\section{Scanning Electron Microscopy (SEM)}

SEM confirmed the light microscopy findings while allowing a more detailed visualization of the glandular lesions. In Group A (Fig. 2a), necrosis, submucosal edema, vasodilation (hypoechoic image) and disruption of collagen fibers were observed.
Pretreatment with cimetidine (Group B, Fig. 2b) and FTL at $0.5 \mathrm{mg} / \mathrm{kg}$ (Group D, Fig. 2d) reduced injury and preserved the mucosal and submucosal structures.

Pretreatment with FTL at $0.25 \mathrm{mg} / \mathrm{kg}$ (Group C, Fig. 3c) and $1 \mathrm{mg} / \mathrm{kg}$ (Group E, Fig. 3e) had no protective effect when compared to Group A (Fig. 3a). Disruption of the connective tissue and vascular proliferation were observed on SEM.

\section{Atomic Force Microscopy (AFM)}

The results of light and SEM were confirmed by AFM. In the AFM analysis, the animals in Group A presented disruption of submucosal layers and collagen fibers, edema and loss of epithelium and villi (Fig. 4a).

The analysis also confirmed the integrity of epithelial and connective tissues in Group B (Fig. 4b) and Group D (Fig. 4d), suggesting a gastroprotective effect of pretreatment with, respectively, cimetidine and FTL at $0.5 \mathrm{mg} / \mathrm{kg}$.

\section{Discussion}

Lectins are glycoproteins with numerous and important applications in biochemistry, cell biology and medicine (Rudiger and Gabius 2001). Frutalin, a lectin extracted from the seeds of $A$. incisa, appears to be no exception.

In this study, the gastroprotective effects of FTL were evaluated histologically using a model of ethanol-induced gastric injury. Only two of the five pretreatments (FTL at $0.5 \mathrm{mg} / \mathrm{kg}$ and cimetidine, a histamine receptor antagonist) had gastroprotective effects. The findings of the histological analysis support the results of previous studies in which FTL was found to be highly gastroprotective against injury induced by ethanol and indomethacin. The observed gastroprotection appears to involve the activation of capsaicin-sensitive gastric afferents, stimulation of endogenous prostaglandins and NO, and the opening of $\mathrm{K}_{\text {ATP }}^{+}$channels (Abdon et al. 2012).

In vivo ethanol-induced injury of the gastric mucosa may lead to surface epithelial exfoliation with loss of barrier, transport, and electrical functions, and hemorrhagic necrosis of the deeper mucosal layers, including progenitor and glandular cells (Tarnawski et al. 1985b; Tamawski et al. 1987). The endothelial cells are damaged within minutes of exposure, resulting in microvascular stasis. The latter is believed to be an important mechanism responsible for deep mucosal necrosis following challenge with ethanol (Szabo et al. 1985; Tarnawski et al. 1985a).

Alcohol consumption is known to lead to acute hemorrhagic gastric erosion in humans. Prolonged use can cause gastritis with mucosal edema, subepithelial hemorrhage, 

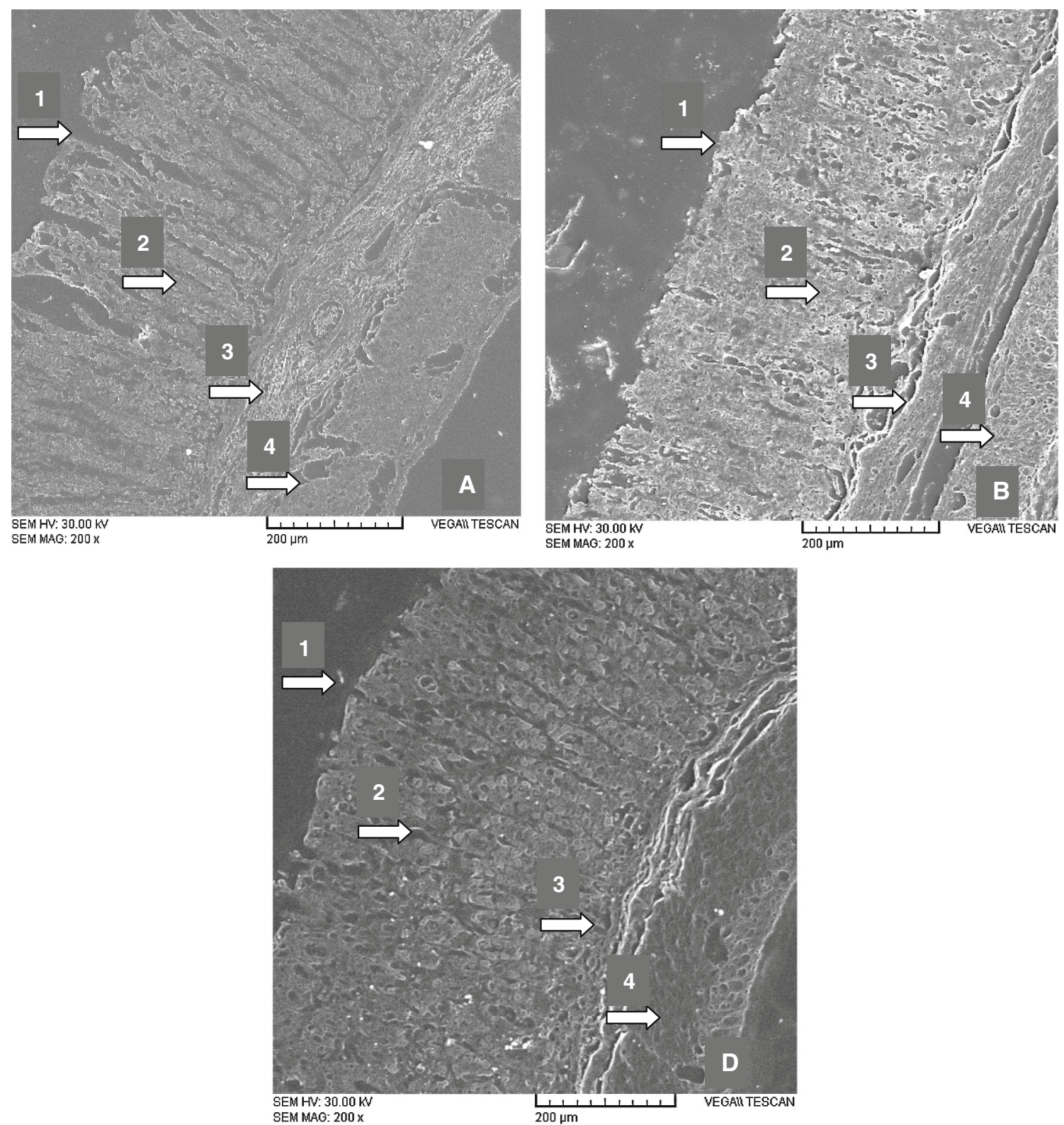

Fig. 2 Histological analysis by scanning electron microscopy (SEM) of gastric tissues in a model of ethanol-induced gastric injury. Magnification $\times 200$. Images showing specific stomach cells. 1 gastric pits, 2 mucosal layer, 3 submucosal layer, 4 muscle layer (smooth

cellular exfoliation and inflammatory cell infiltration (Matsuhashi et al. 2007).

Our histological findings confirmed the gastroprotective effect of FLT on the gastric mucosa of mice, suggesting cytoprotective action. In an earlier macroscopic analysis (Abdon et al. 2012), FTL afforded non-dose-related gastroprotection against ethanol-induced injury.

Three-dimensional high-resolution images of the stomach made with SEM and AFM are very useful in the evaluation of surface tissue structures. These techniques muscle); a saline solution (negative control, Group A), b cimetidine at $100 \mathrm{mg} / \mathrm{kg}$ (positive control, Group B), and d FTL at $0.5 \mathrm{mg} / \mathrm{kg}$ (Group D)

have over the past two decades become indispensable tools in a number of health-related areas. For example, pharmacological research on new drugs requires extensive knowledge of the mechanisms, toxicity and microstructural aspects involved in order to understand the interaction between drugs and target tissues, especially the mucosa (Deacon et al. 2000).

The microscopic capabilities of SEM and AFM allowed to observe the microstructure of the stomach surface exposed to ethanol and confirm the gastroprotective effect 

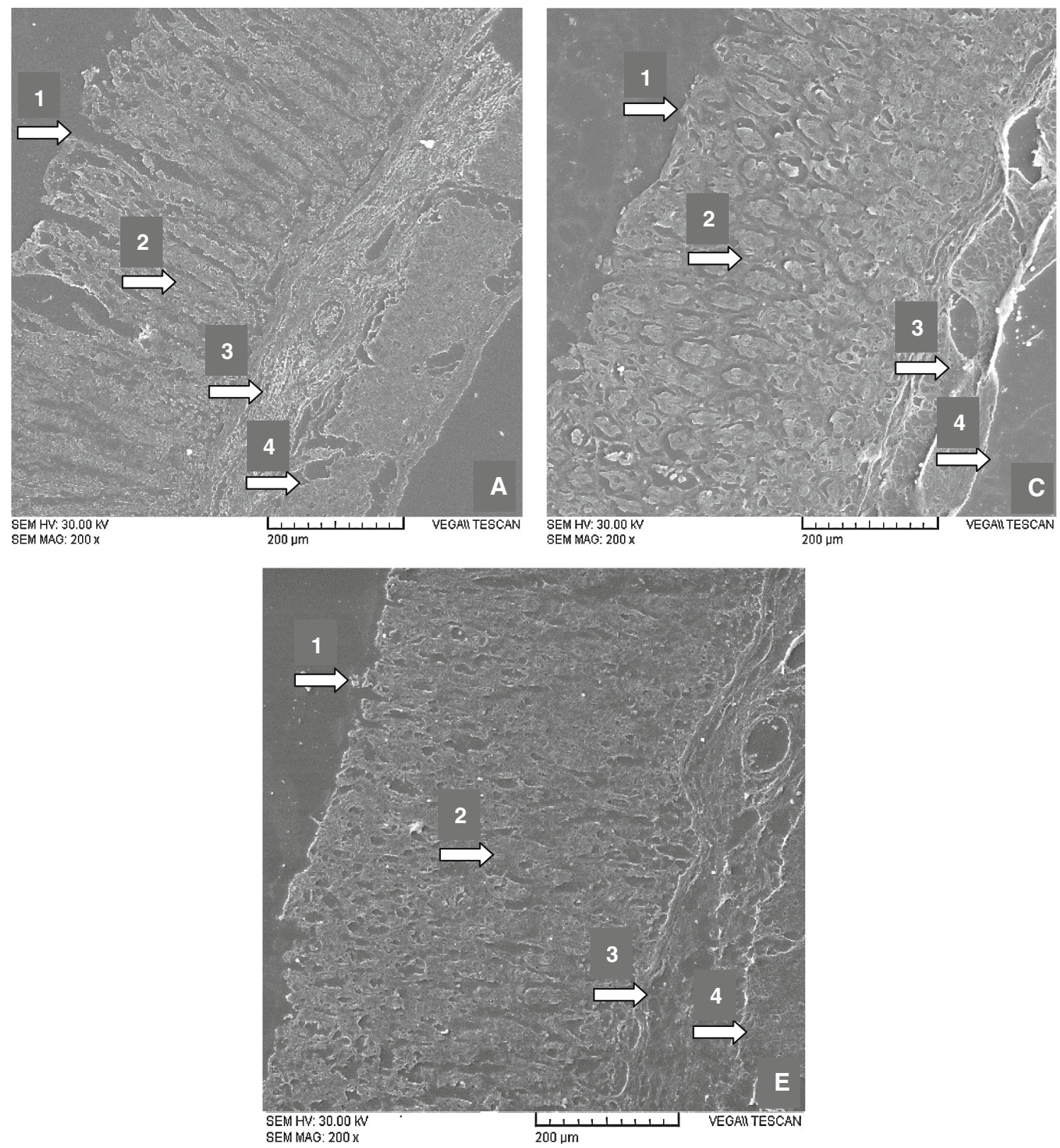

Fig. 3 Histological analysis by scanning electron microscopy (SEM) of gastric tissues in a model of ethanol-induced gastric injury. Magnification $\times 200$. Images showing specific stomach cells. 1 gastric

of pretreatment with FTL, as previously described by Abdon et al. (2012).

In the present study, administration of FTL at $0.5 \mathrm{mg} / \mathrm{kg}$ significantly reduced gastric injury, preventing damage (lymphocyte infiltration, necrosis, desquamation and disruption of the mucosal layers and collagen fibers) otherwise observed in control group. FTL produced a biphasic trend, with decreasing gastroprotection in higher dose. This may reflect that FTL have two different and opposed actions or partial agonist activity at their receptors (Kekesi et al. 2004). A similar result was found by Figueiredo et al. pits, 2 mucosal layer, 3 submucosal layer, 4 muscle layer (smooth muscle); a saline solution (negative control, Group A), c FTL at $0.25 \mathrm{mg} / \mathrm{kg}$ (Group C), and e FTL at $1.0 \mathrm{mg} / \mathrm{kg}$ (Group E)

(2009). They demonstrated that the lectin Cbol, from (Canavalia boliviana seeds) presented a bell-shaped curve in the second phase of formalin test.

The gastroprotective effect of FTL involves multiple factors acting on the gastric microcirculation and cytoprotection promoted through the activation of capsaicin (TRPV)-sensitive gastric afferents, the stimulation of endogenous prostaglandins and $\mathrm{NO}$, and the opening of $\mathrm{K}_{\mathrm{ATP}}^{+}$channels (Abdon et al. 2012).

The stimulation of gastric capsaicin receptors (TRPV1) leads to the release of substance $\mathrm{P}$, somatostatin and 

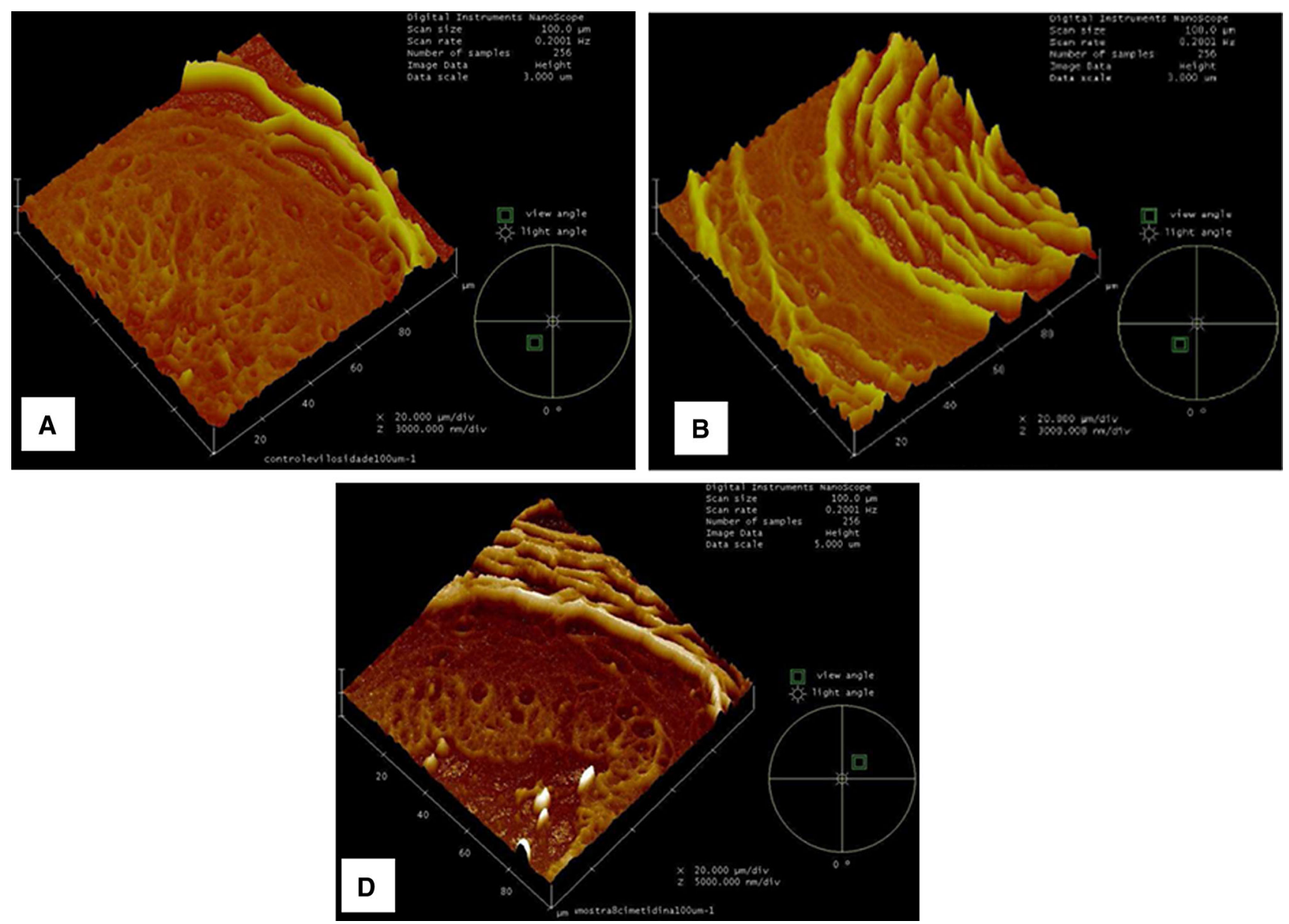

Fig. 4 Histological analysis by atomic force microscopy (AFM) of gastric tissues in a model of ethanol-induced gastric injury. Magnification $\times 200$. a saline solution (negative control, Group A), b cimetidine at $100 \mathrm{mg} / \mathrm{kg}$ (positive control, Group B), and d FTL at $0.5 \mathrm{mg} / \mathrm{kg}$ (Group D)

calcitonin gene-related peptide (CGRP) and to the inhibition of gastrin production. The TRPV1-expressing nerve fibres are activated when the protective mucus barrier is disrupted and acid comes into contact with the lamina propria. This activation releases CGRP and NO, thereby promoting mucosal hyperemia and facilitating the activation of other defense mechanisms, such as bicarbonate secretion and inhibition of gastric acid secretion (Guedes et al. 2008).

The mechanisms of gastric self-protection depend on adequate blood flow due to the intense metabolic activity and the oxygen needs of the gastric mucosa. Therefore, an increase in blood flow following disruption of the protective barrier and retrodiffusion of $\mathrm{H}^{+}$ions to the mucosal cells is of utmost importance (Maity et al. 2003). The control of gastrointestinal blood flow is largely attributed to the action of endogenous prostaglandins (Funatsu et al. 2007), but prostaglandins also help maintain the integrity of the gastric mucosa by inhibiting acid secretion, stimulating mucus and bicarbonate secretion, inhibiting mastocyte activation, reducing leucocyte adherence to the vascular endothelium and inhibiting apoptosis (Batista et al. 2004).

In addition, NO plays an important role in gastrointestinal defense because of its ability to increase mucosal blood flow, produce mucus and inhibit the adherence of neutrophils to endothelial cells (Coruzzi et al. 2000).

Using SEM and AFM, desquamation of the collagen of the gastric epithelium induced by exposure to ethanol was observed in control group but not in pretreated with FTL $(0.5 \mathrm{mg} / \mathrm{kg})$. Collagen helps support the epithelial cells of the gastric mucosa during acute injury. Thus, an increase in mucosal collagen can enhance resistance against lesion progression (Arisawa et al. 2006).

Apart from these mechanisms, recent studies based on different models of gastric injury have revealed reactivity to neutrophils, excessive recruitment and metabolic activation (Fialkow et al. 2007). Thus, FTL has been shown to promote neutrophil migration, induce chemotaxis and trigger oxidative burst. These effects are believed to favor 
FTL-promoted gastroprotective activity (Brando-Lima et al. 2005).

A number of studies have evaluated the ability of antioxidants to protect the gastric mucosa in gastric ulcer models (Potrich et al. 2010), but antioxidant activity is not likely to have played a role in the gastroprotection observed in the present study. In fact, in a previous study, FTL displayed no antioxidant activity, based on glutathione and malondialdehyde measurements (Abdon et al. 2012).

\section{Conclusion}

In conclusion, FTL displayed gastroprotective activity against ethanol-induced gastric injury, preventing the formation of gastric ulcer and reducing epithelial desquamation, glandular damage, mucosal necrosis and infiltration. The observed effects appear to be due to mechanisms previously described for frutalin.

Acknowledgments The authors would like to thank CNPq, Funcap and Fundação Edson Queiroz for financial support.

Conflict of interest The authors report no conflicts of interest.

\section{References}

Abdel-Salam OME, Czimmer J, Debreceni A et al (2001) Gastric mucosal integrity: gastric mucosal blood flow and microcirculation. An overview. J Physiol Paris 95:105-127

Abdon APV, Coelho de Souza G, Coelho de Souza LN et al (2012) Gastroprotective potential of frutalin, a D-galactose binding lectin, against ethanol-induced gastric lesions. Fitoterapia 83:604-608

Arisawa T, Shibata T, Kamiya Y et al (2006) Effects of sucralfate, cimetidine and rabeprazole on mucosal hydroxyproline content in healing of ethanol-HCL-induced gastric lesions. Clin Exp Pharmacol Physiol 33:628-632

Batista LM, Almeida AB, Pietro ML et al (2004) Gastric antiulcer activity of Syngonanthus arthrotrichus Silveira. Biol Pharm Bull 27:328-332

Borrelli F, Izzo AA (2000) The plant kingdom as a source of antiulcer remedies. Phytother Res 14:581-591

Brando-Lima AC, Saldanha-Gama RF, Henriques MGMO et al (2005) Frutalin, a galactose-binding lectin, induces chemotaxis and rearrangement of actin cytoskeleton in human neutrophils: involvement of tyrosine kinase and phosphoinositide 3-kinase. Toxicol Appl Pharmacol 208:145-154

Campana PT, Moraes DI, Monteiro-Moreira ACO et al (2002) Unfolding and refolding studies of frutalin, a tetrameric Dgalactose binding lectin. Eur J Biochem 269:753-758

Coruzzi G, Adami M, Morini G et al (2000) Antisecretory and gastroprotective activities of compounds endowed with $\mathrm{H}_{2}$ antagonistic and nitric oxide (NO) donor properties. J Physiol Paris 94:5-10

Deacon MP, Mcgurk S, Roberts CJ et al (2000) Atomic force microscopy of gastric mucin and chitosan mucoadhesive systems. Biochemistry 384:557-563
Fialkow L, Wang Y, Downey GP (2007) Reactive oxygen and nitrogen species as signaling molecules regulating neutrophil function. Free Radic Biol Med 42:153-164

Figueiredo JG, Bitencourt FS, Beserra IG et al (2009) Antinociceptive activity and toxicology of the lectin from Canavalia boliviana seeds in mice. Naunyn Schmiedebergs Arch Pharmacol 380:407-414

Funatsu T, Chono K, Hirata T et al (2007) Mucosal acid causes gastric mucosal microcirculatory disturbance in nonsteroidal anti-inflammatory drug-treated rats. Eur J Pharmacol 554:53-59

Guedes MM, da Carvalho AC, Lima AF et al (2008) Gastroprotective mechanisms of centipedic acid, a natural diterpene from Egletes viscosa LESS. Biol Pharm Bull 31:1351-1355

Jagtap UB, Bapat VA (2010) Artocarpus: a review of its traditional uses, phytochemistry and pharmacology. J Ethnopharmacol 129:142-166

Johnson AP, Clark JB, Osborn MF (1983) Scanning electron microscopy of the interaction between Haemophilus influenzae and organ cultures of rat trachea. J Med Microbiol 16:477-482

Kekesi G, Joo G, Csullog E et al (2004) Dose-independent antinociceptive interaction of endogenous ligands at the spinal level. Brain Res 1029:93-102

Maity P, Biswas K, Roy S et al (2003) Smoking and the pathogenesis of gastroduodenal ulcer-recent mechanistic update. Mol Cell Biochem 253:329-338

Matsuhashi T, Otaka M, Odashima M et al (2007) Protective effect of a novel rice extract against ethanol-induced gastric mucosal injury in rat. Dig Dis Sci 52:434-441

Moreira RA, Castelo-Branco CC, Monteiro AC et al (1998) Isolation and partial characterization of a lectin from Artocarpus incisa $\mathrm{L}$. seeds. Phytochemistry 47:1183-1188

Potrich FB, Allemand A, Silva LM et al (2010) Antiulcerogenic activity of hydroalcoholic extract of Achillea millefolium L.: involvement of the antioxidant system. $\mathrm{J}$ Ethnopharmacol 130:85-92

Robert A, Nezamis JE, Lancaster C et al (1979) Cytoprotection by prostaglandins in rats: prevention of gastric necrosis produced by alcohol, $\mathrm{HCl}, \mathrm{NaOH}$, hypertonic $\mathrm{NaCl}$ and thermal injury. Gastroenterology 77:433-443

Rudiger H, Gabius HJ (2001) Plant lectins: occurrence, biochemistry, functions and applications. Glycoconj J 18:189-613

Sánchez-Mendoza ME, Reyes-Ramírez A, Cruz Antonio L et al (2011) Bioassay-guided isolation of an anti-ulcer compound, Tagitinin C, from Tithonia diversifolia: role of nitric oxide, prostaglandins and sulfhydryls. Molecules 16:665-674

Silva MS, Almeida ACA, Farias FM et al (2010) Abarema cochliacarpos: gastroprotective and ulcer-healing activities. J Ethnopharmacol 132:134-142

Szabo S, Trier JS, Brown A et al (1985) Early vascular injury and increased vascular permeability in gastric mucosal injury caused by ethanol in the rat. Gastroenterology 88:228-236

Tamawski A, Hollander D, Stachura J et al (1987) Alcohol injury to the normal human gastric mucosa: endoscopic histologic and functional assessment. Clin Invest Med 10:259-263

Tarnawski A, Hollander D, Gergely H (1985a) Ethanol-induced gastric mucosal injury: sequential analysis of morphologic and functional changes. Gastroenterol Clin Biol 9:88-92

Tarnawski A, Hollander D, Stachura J et al (1985b) Prostaglandin protection of the gastric mucosa against alcohol injury, a dynamic time-related process. Role of the mucosal proliferative zone. Gastroenterology 89:366-374

Vera-Arzave C, Cruz Antonio L, Arrieta J et al (2012) Gastroprotection of suaveolol, isolated from Hyptis suaveolens, against ethanol-induced gastric lesions in wistar rats: role of prostaglandins, nitric oxide and sulfhydryls. Molecules 17:8917-8927 